\title{
INTERNAL ENVIRONMENTAL CHARACTERISTICS OF A CHIRIBAYA STYLE TOMB HOLDING SWINE REMAINS AND THEIR TAPHONOMIC IMPACT ON DECOMPOSITION DELAY, A REQUISIT FOR MUMMIFICATION
}

\author{
Alison Marissa Brooks Garcia ${ }^{1}$, Ronald G. BecketT ${ }^{2}$, \\ JAMES T. WATSON ${ }^{3}$ \\ ${ }^{1}$ School of Anthropology, University of Arizona, Tucson, Arizona, USA \\ ${ }^{2}$ Bioanthropology Research Institute, Quinnipiac University, \\ Hamden, Connecticut, USA \\ ${ }^{3}$ Arizona State Museum and School of Anthropology, University of Arizona, \\ Tucson, Arizona, USA
}

\begin{abstract}
Attempts have been made to better understand the mummification processes associated with the pre-Inca culture known as the Chiribaya. The ancient Chiribaya used various textile wrappings that likely enhanced wicking of fluids out of the body thus increasing the potential for mummification. Here we examine the tomb environment itself as a probable factor in the potential mummification of human remains. To reveal more about the Chiribaya mummification process, we replicated the physical characteristics of a Chiribaya tomb in the Sonoran Desert and monitored the intra-tomb environmental changes while occupied by a swine analogue. Two identical tombs were constructed using concrete fence block measuring 152.4 by 91.4 centimeters ( 5 by 3 feet) and 91.4 centimeters ( 3 feet) deep. Tomb caps were constructed from frame mounted concrete backer board. Two data loggers for temperature and relative humidity were placed within each of the tombs. A freshly deceased 68 kilogram (150 pound) swine was wrapped in wool fabric to allow for wicking of body fluids and placed in the experimental tomb. Capped PVC access ports were introduced into the experimental tomb allowing for periodic endoscopic access. Both tombs were buried at a depth of approximately 76.2
\end{abstract}


centimeters (30 inches). The experimental tomb was monitored endoscopically to collect visual data on the condition of the swine analogue. The tombs remained buried for 95 days. The stage of decomposition was determined by the physical findings of the swine upon excavation and compared to literature reports of decomposition rates in the Sonoran Desert. Based on our observational and endoscopic data, overall mummification did not occur; however, some mummification was seen on the right jowl and the gravity dependent low pelvic region upon exhumation. This visual data allowed us to directly observe the intra-tomb processes and is correlated with data-logger information from both tombs providing us a better understanding of the associated intra-tomb environmental variations. Further, the experiment demonstrates the taphonomic impact of these artificial subterranean environments on rate of decomposition and offers insight as to how the Chiribaya tombs encouraged mummification.

Keywords: mummification, endoscopy, Chiribaya, taphonomy, Sonoran Desert

\section{INTRODUCTION}

Currently, little is known about the pre-Inca culture known as the Chiribaya. The limited amount of literature about the Chiribaya culture suggests that by approximately $1250 \mathrm{CE}$, they had established several villages from northern Chile to the mountains in southern Peru. A major portion of what remains from their culture is a multitude of tombs containing natural mummies preserved by the arid climate in the area. Extensive research in other parts of the world has discovered that understanding different aspects of the death practices of extinct cultures plays a crucial role in reconstructing adaptations and variability in human-environment interactions.

Chiribaya mummies are primarily 'natural' or spontaneous mummies. Mummies in this category are produced as a result of nature, more specifically, the impact of the environment where the body was interred (1). There are many environments and conditions that will halt or greatly impede the normal process of decomposition resulting in mummified remains. In most cases with natural mummification, there has been no exogenous attempt to preserve the body either externally or internally.

Natural mummification, which most often occurs in dry and arid climates such as deserts or arctic regions, is usually the end result of tissue that has survived the decomposition process. Once the tissue has become dry and desiccated, it offers less nutritional value, making insect and scavenger activity 
nonexistent (9). Humidity levels are an important factor in the mummification process, and they certainly played a significant role in the preservation of the ancient Chiribaya.

The Chiribaya culture thrived in what is today known as the Department of Moquegua, a southern coastal valley of Peru (6). The aridity of the Peruvian climate would have easily ceased active decomposition, resulting in natural mummification.

In 2009, Janaway et al. published a study titled Taphonomic Changes to the Buried Body in Arid Environments: An Experimental Case Study in Peru, with an aim to understand the effects of burial over relatively short timescales (7). Specifically, the experiment included a focus on the early phases of natural mummification in a tomb structure. Similarly, in order to reveal more about the Chiribaya mummification process, we replicated the physical characteristics of a Chiribaya tomb in the Sonoran Desert and monitored the intra-tomb environmental changes while occupied by a swine analogue. In this paper we examine the tomb environment itself as a probable factor in the potential mummification of human remains. The Janaway experiment monitored their subject by frequently opening the tomb structure in order to make physical observations, which ultimately led to compromised results. Exposure to the outside elements would likely have profound impact on the decomposition and mummification processes. In an effort to maintain stability during observations and to obtain more accurate results, we conducted these observations using less invasive endoscopic imaging, allowing for more reliable data collection. Although the Sonoran and Atacama Deserts have different environmental characteristics, changing environmental conditions within the experimental tomb when compared to a control tomb help us better understand the inter-tomb variations.

\section{MATERIALS AND METHODS}

\section{Location}

The experiment took place at the University of Arizona's West Campus Agricultural Center in Tucson, Arizona (lat: 32N 15'31", long: -111W 0' 29") near the Santa Cruz River. The Sonoran Desert location was selected for its convenience and for the ability to secure the area. Chiribaya tombs are situated in the Osmore River Valley of Peru, so the proximity to the Santa Cruz River was considered an advantage. The terrain was undisturbed Sonoran Desert. The soil composition was analyzed by Skyline Laboratories of Tucson to determine the presence of excess amounts of elements that would encourage mummification including arsenic, copper, mercury, lead, nitrates and salts. The soil was sampled 
at two levels, the topsoil and the bottom layer of the tomb. These findings are presented in the results section of this paper.

\section{Burial tombs and instrumentation}

The burial tombs were dug using a mechanical backhoe. One experimental tomb and an identical control tomb were constructed using concrete fence blocks. Both tombs measured 152.4 by 91.4 centimeters ( 5 by 3 feet) and 91.4 centimeters ( 3 feet) deep. Tomb caps were created from frame-mounted concrete backer board (Fig. 1). Two data loggers for temperature and relative humidity were placed within each of the tombs with the possibility that one could fail in mind. The data loggers used in this study were Fourtec MicroLite Temperature and RH with LCD model \# Lite5032P-RH. The data loggers were affixed to a wooden stake within each tomb to assure that readings were taken at approximately mid-depth of each tomb and on the opposite wall from the swine analogue. The freshly deceased swine wrapped in wool fabric was placed into the experimental tomb. Capped PVC access ports were introduced into the experimental tomb, allowing for periodic endoscopic access. Both the experimental tomb and the control tomb were buried at a depth of approximately 76.2 centimeters (30 inches). Intra-tomb illumination was accomplished by using a modified microwave oven bulb wired to a power inverter. The experimental tomb was monitored endoscopically at varied intervals to collect visual data on the condition of the swine analogue. Observations were also made to assess the immediate area for evidence of predation or predation attempts. The tombs remained buried for ninety-five days.

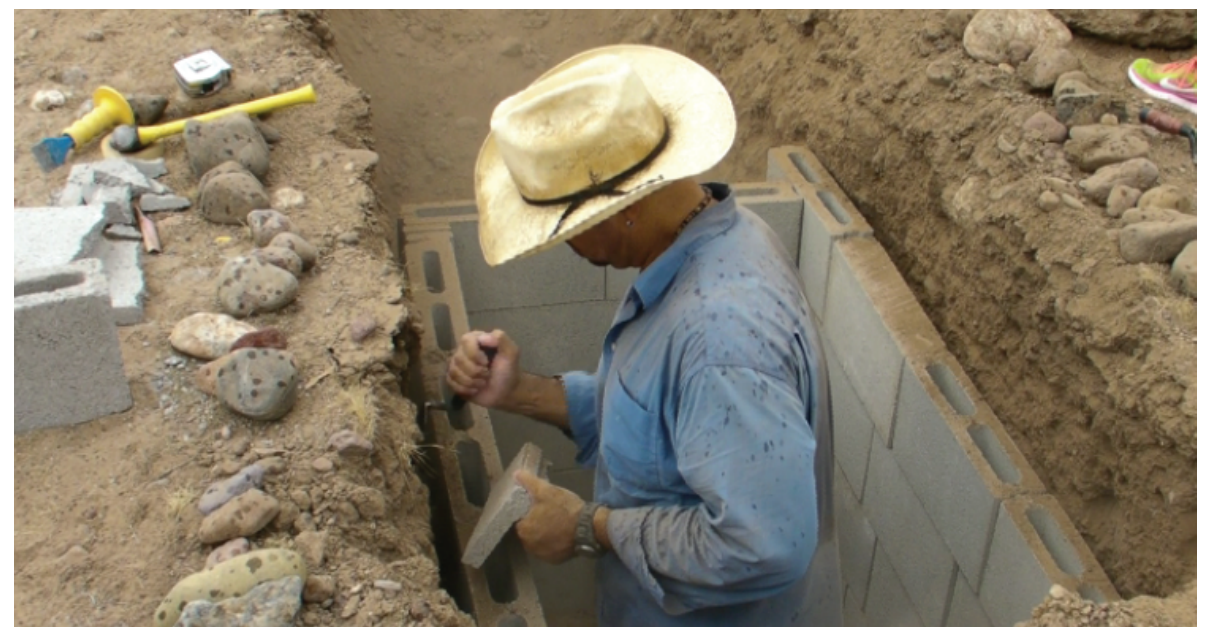

Figure 1. Burial tomb construction (see text for details). 


\section{Swine Analog}

Pigs are common human cadaver analogues and prove particularly useful when studying soft tissue decomposition. Pigs and humans share many similar anatomical characteristics, including skin structure, fat-to-muscle ratio, and comparable gut chemistry, as well as sizes of the thoracic cavities $(7,8)$. The approximately 68 kilogram (150 pound) swine was obtained from a slaughter farm 135 kilometers (84 miles) outside of Tucson. The time interval from harvesting to burial was within two hours of death. The ancient Chiribaya used various textile wrappings that likely enhanced wicking of fluids out of the body, enhancing the potential for mummification. The experimental corpse was tightly bundled in a wool fabric to allow for wicking of body fluids. It took two people to place the pig into the tomb. It was placed on top of a tarp and carefully lowered into the ground, with one person holding the sides of the tarp on either side of the margins of the pit. Once the pig was placed at the bottom of the tomb, the tarp was carefully pulled out from under the corpse and one person in the tomb situated the pig upright (Fig. 2), similar to the posture used by the Chiribaya. Due to the hot and humid climate of the Sonoran Desert during the rainy season, it was crucial to the results of the experiment that the swine analog be entombed as efficiently as possible after death.

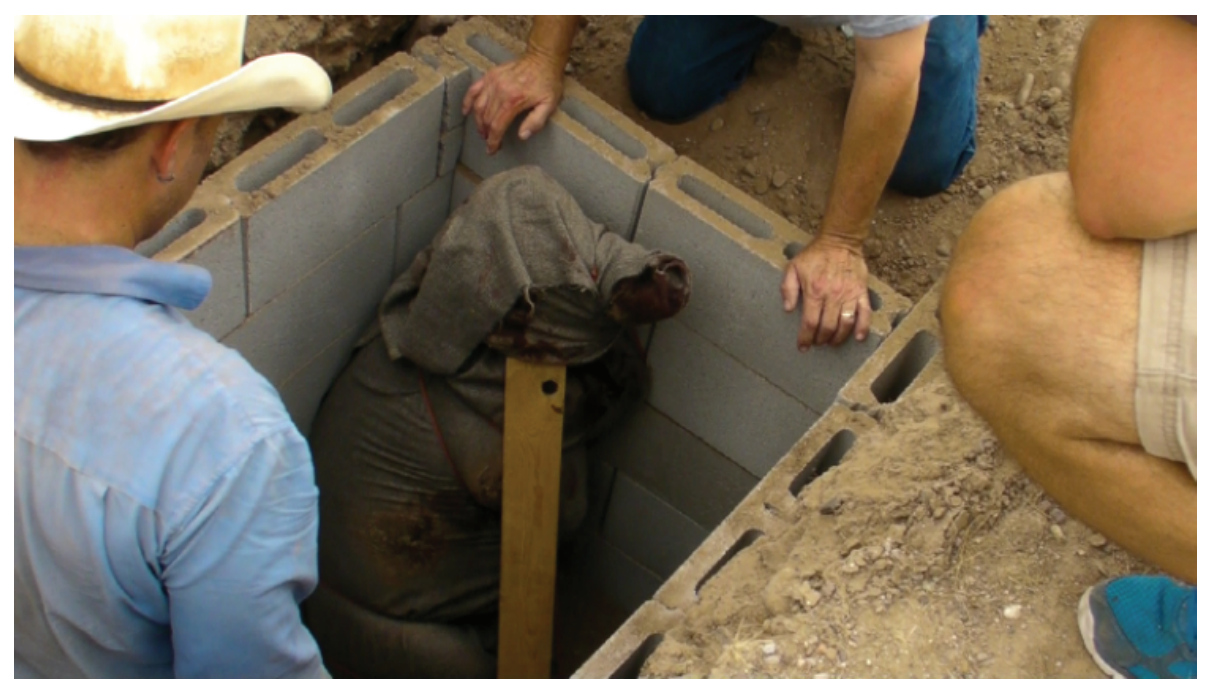

Figure 2. Placement of swine analogue in experimental burial tomb. 


\section{Observational Intervals}

Once interred, site and endoscopic observations were made and recorded at 9 days, 12 days, 18 days, 33 days, 61 days, and 75 days, with the body being exhumed on the $95^{\text {th }}$ day. Following exhumation, the data loggers were retrieved and analyzed. A detailed inspection of the condition of the body was made. The stage of decomposition was determined by the physical findings of the swine upon exhumation and compared to literature reports of decomposition rates in the Sonoran Desert and other similar studies. The stage of decomposition determination used in this study was modeled using the categories and stages of decomposition presented by Galloway (4) who assessed decomposition rates for surface burials of humans in the Sonoran Desert region.

\section{RESULTS}

Direct observational data of the site and endoscopic data on the intra-tomb environment were collected at regular intervals throughout the experimental period. Final observations were made at exhumation at which time the data was retrieved from the data loggers.

\section{Surface and endoscopic observations}

Day 9: Endoscopic images demonstrated that a fluid trail (Fig. 3) had begun to appear at the base of the tomb, suggesting that the subject had entered the putrefaction stage. Because it had been tightly bundled in a wool blanket, color changes were impossible to note, however, since gases in the abdomen had forced out bodily fluids, putrefaction was clear. The nauseatingly sweet odor arising from the PVC observation port was another clear indication of putrefaction. Additionally, there was evidence of attempted predation with shallow holes dug into the surface directly above the experimental subject. Scat and prints were also observed. No predation attempts were apparent at the control tomb site.

Day 12: The fluid trail had grown and the subject began to slump down (Fig. 4) from its initial upright position. The subject had entered the black putrefaction stage, which typically occurs between ten and twenty days after death, depending on region and temperature. Bloating had decreased significantly, as the abdominal gases had been expelled, resulting in the slumped posture. 


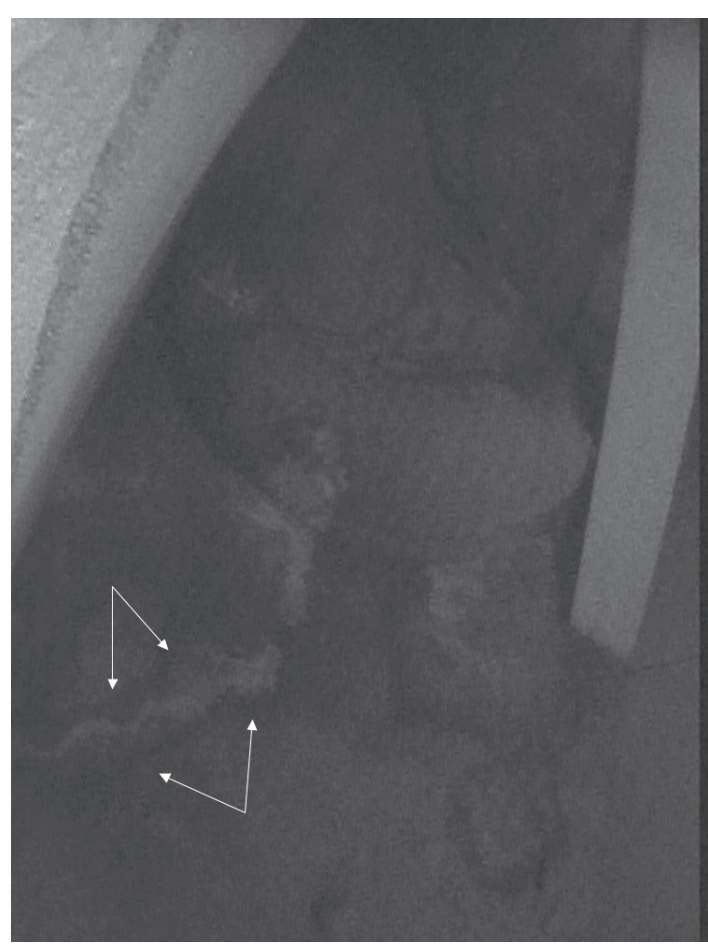

Figure 3. Endoscopic image of initial fluid trail (arrows) appearing day 9.

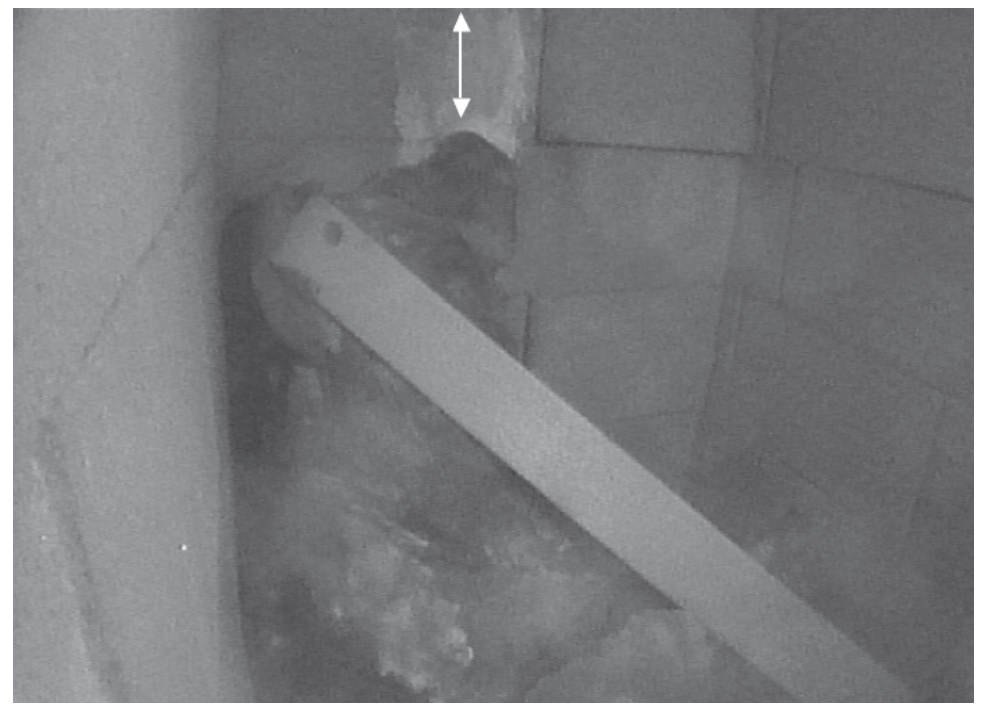

Figure 4. Endoscopic image of initial slumping of swine body indicated by arrows suggesting body cavity collapse at day 12 . 
Day 18: Wicking had begun to appear on the wool wrapping; however, there was no further slumping of the corpse.

Day 33: The subject had collapsed significantly. Also noted was a great deal of white residue on the walls of the tomb, as well as moisture on the endoscope. The odor changed from sweet to rancid. Subterranean termite tubes were observed on the walls of the experimental tomb.

Day 61: The amount of body fluids on the tomb floor increased dramatically and there was further slumping of the corpse (Fig. 5). Moisture continued to appear on the endoscope after observation and the odor once again changed, bearing a strong similarity to refuse decay.

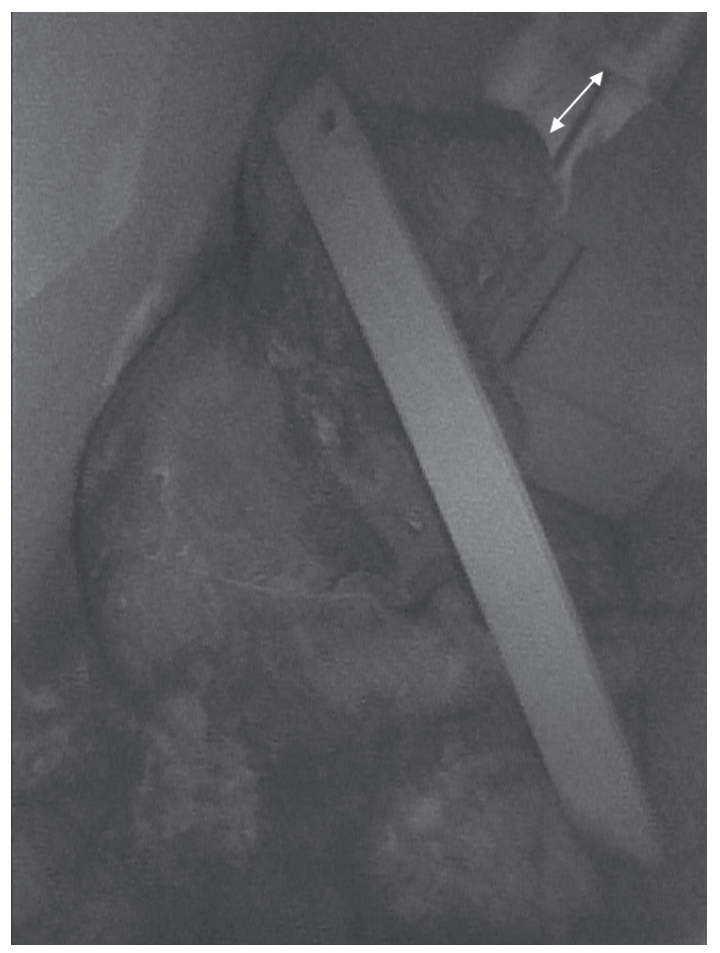

Figure 5. Endoscopic image of increased slumping (arrow) of the swine body at day 61 .

Day 75: The major change at this observation was an apparent stabilization of the subject and the tomb environment. The fluid pool had not grown and there was no significant positional change of the subject. Less moisture was present on the endoscope and the odor had become markedly less severe.

Day 95 - Exhumation: Upon exhumation (Fig. 6), the corpse was found to be in various states of decay related to gravity dependence. The less gravity dependent portions, the head and neck regions, were stiff and in the early 
stages of mummification. The torso presented with caseous internal organs suggesting the putrefaction stage of decomposition. Interestingly, the most gravity dependent portions, the haunches, appeared to have undergone some degree of saponification usually seen in the butyric fermentation stage (Fig. 7). While no insect infestation was observed during the observational period, a few pupa casings were discovered at exhumation.
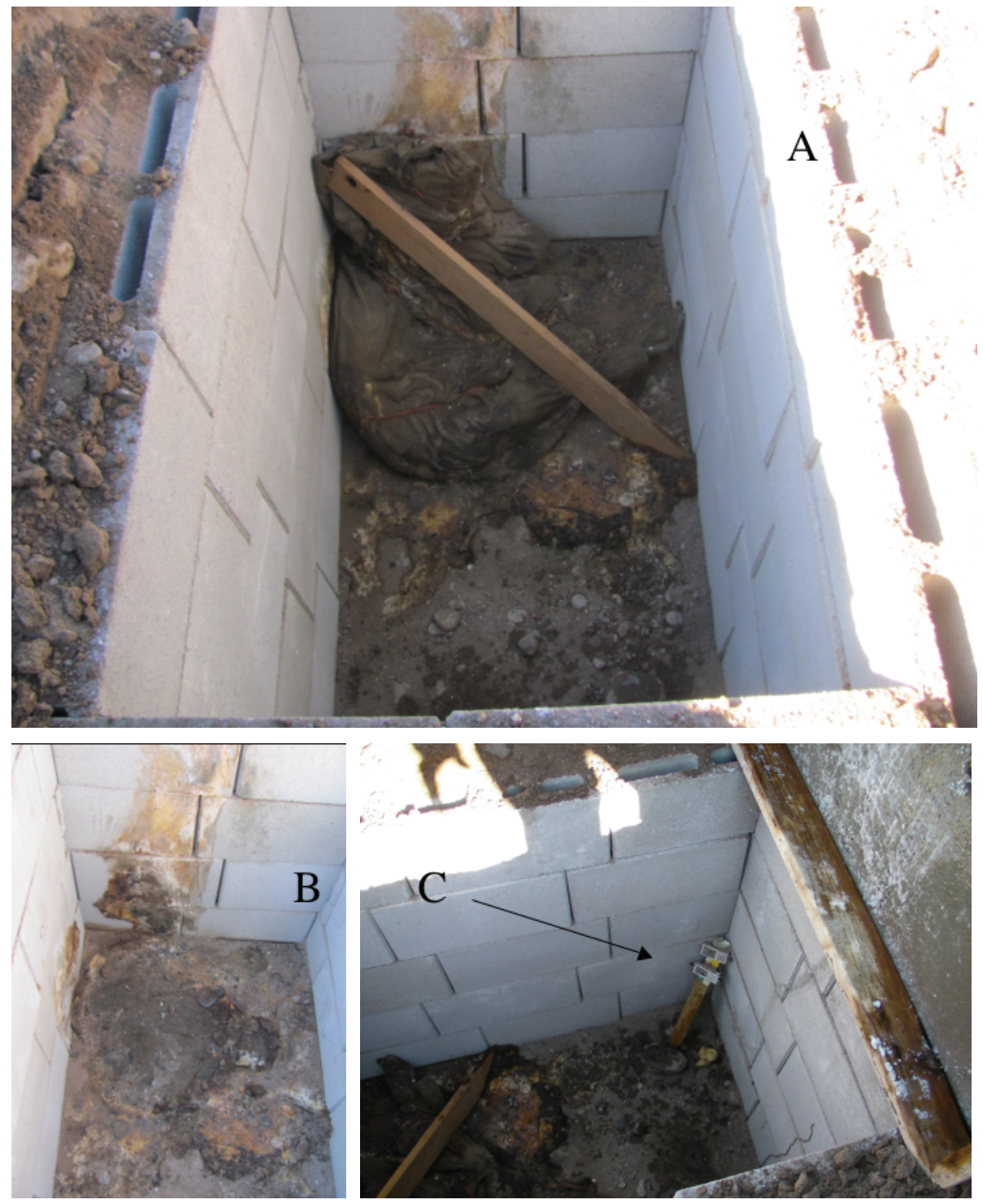

Figure 6. Appearance of swine in tomb at excavation (A), fluid pattern on tomb floor following exhumation (B) at day 95 , and data logger positioning (C, arrow). 


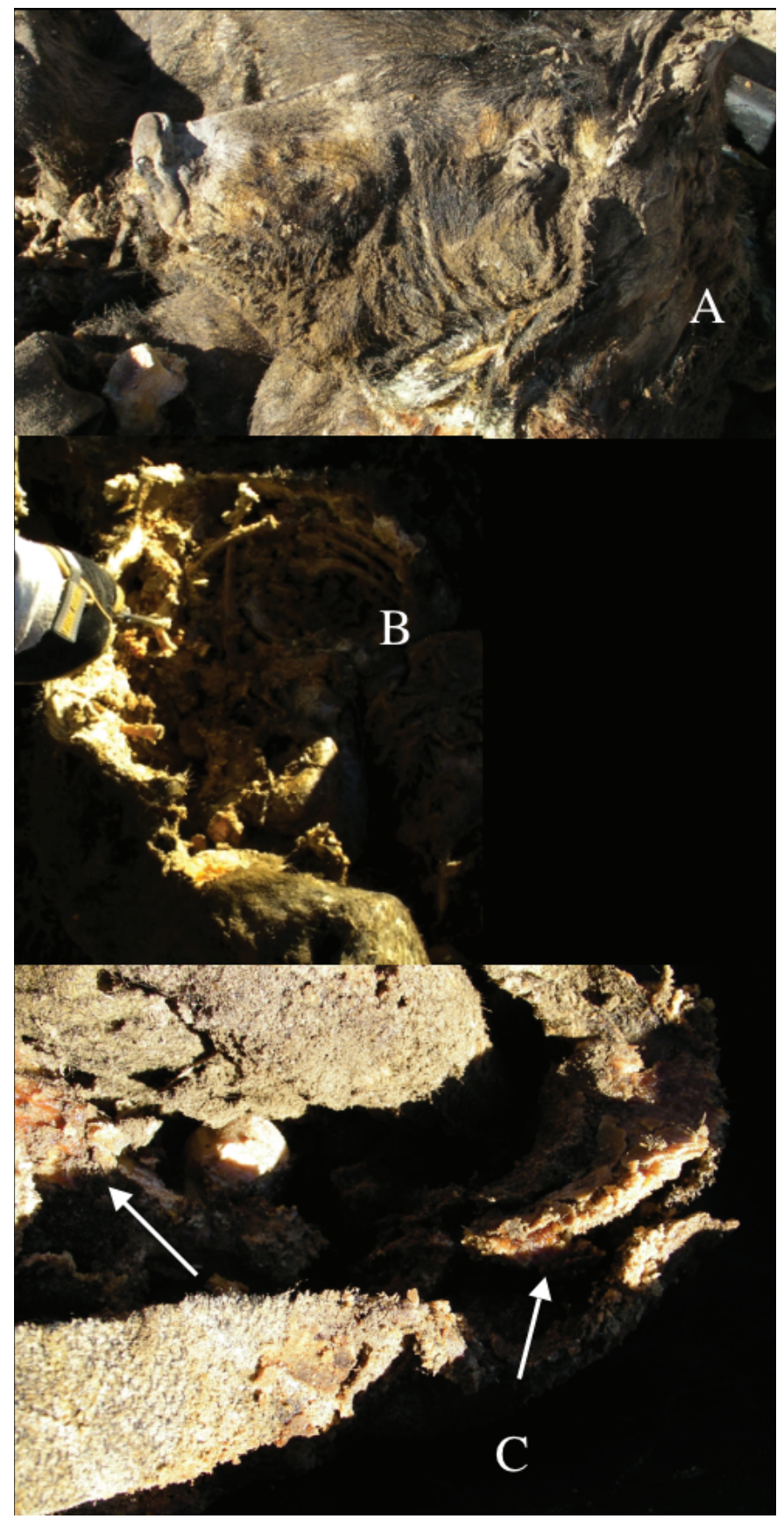

Figure 7. Varied states of preservation/decomposition seen at exhumation due to gravity dependence: mummified skin at non-gravity depended regions $(A)$, caseation of intra-thoracic structures $(B)$, and saponification in gravity dependent regions (C, arrows). 
Data Loggers Data: One data logger in the experimental tomb experienced failure after 14 days in use. Fortunately, the second data logger in that tomb remained functional throughout the experimental cycle. The pattern of moisture loss from the corpse was apparent as compared to control tomb data. A total of 364 measurements were acquired by each functional data logger in each of the tombs (Fig. 8). Although the temperature and relative humidity patterns were similar between the experimental and control tombs the experimental tombs demonstrated consistently higher values for each of the measured variables. Statistical analysis demonstrates a statistically significant difference between the experimental and control tombs for both temperature $(\mathrm{t}=7.3189, \mathrm{df}=$ $726, \mathrm{p}<0.001)$ and relative humidity $(\mathrm{t}=29.815, \mathrm{df}=726, \mathrm{p}<0.001)$. Through the course of this study, the average daytime ambient temperature was $27.78 \mathrm{C}$ ( $82 \mathrm{~F}$ ) with an average $\mathrm{RH}$ of $20 \%$. The experimental tomb average temperature was $29.17 \mathrm{C}(84.5 \mathrm{~F})$ with an average $\mathrm{RH}$ of $97.42 \%$. The control tomb average temperature was $26.81 \mathrm{C}(80.25 \mathrm{~F})$ with an average $\mathrm{RH}$ of $85.44 \%$.

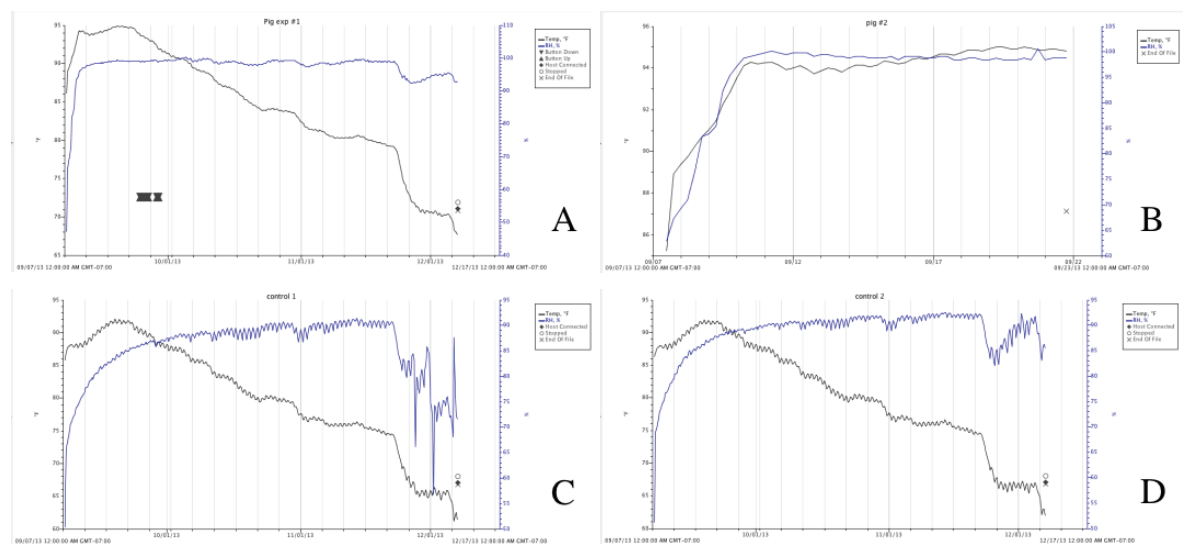

Figure 8. Data logger graphic data for experimental tomb (A and B) and control tomb $(C$ and $D)$. Note that in tracing $B$ the data logger failed after 14 days.

Soils analysis: The topsoil and the bottom tomb layer were sampled with the analysis of forty-nine elements. The results of the analysis of elements related to this study are presented in Table 1. 
Table 1. Soil analysis for heavy metals and salts

\begin{tabular}{lcc}
\hline Element & Topsoil $-\mathrm{ppm} / \%$ & Bottom soil $-\mathrm{ppm} / \%$ \\
\hline $\mathrm{As}$ & 9.7 & 10.7 \\
\hline $\mathrm{Ca}$ & $0.77 \%$ & $0.84 \%$ \\
\hline $\mathrm{Cu}$ & 31.4 & 23.7 \\
\hline $\mathrm{Hg}$ & 0.289 & 0.141 \\
\hline $\mathrm{K}$ & $0.21 \%$ & $0.19 \%$ \\
\hline $\mathrm{Mg}$ & $0.33 \%$ & $0.30 \%$ \\
\hline $\mathrm{Na}$ & $0.10 \%$ & $0.09 \%$ \\
\hline $\mathrm{Ni}$ & 11.0 & 8.9 \\
\hline $\mathrm{Pb}$ & 19.9 & 19.3 \\
\hline $\mathrm{S}$ & $0.18 \%$ & $0.10 \%$ \\
\hline $\mathrm{Zn}$ & 45.0 & 43.0 \\
\hline
\end{tabular}

\section{DISCUSSION}

\section{Decomposition rates in Sonoran Desert}

The stage of decomposition determination used in this study was modeled using the categories and stages of decomposition presented by Galloway (4) who assessed decomposition rates for surface burials of humans in the Sonoran Desert region.

Those stages include: Fresh Decay (stage 1) where no discoloration or insect activity is found. The next is Early Decomposition (stage 2 ) which is a continuum of changes starting with a pink-white appearance, some skin slippage and some hair loss followed by a gray to green discoloration with some flesh remaining relatively fresh. The continuum of stage 2 continues with a discoloration from the gray to green to brownish shades particularly at fingers, nose and ears with some flesh still relatively fresh. The final descriptions of early decomposition at the end of its continuum include bloating with green discoloration. Post bloating features appear following a rupture of the abdominal gases with discoloration moving from green to dark brown, followed by a black discoloration of the arms and legs with the skin having a leathery appearance.

In Advanced Decomposition (stage 3) tissue decay produces sagging of the flesh, and caving in of the abdominal cavity, often accompanied by extensive maggot activity. Moist decomposition in which there is bone exposure follows with some mummification as well as some retention of internal structures. If there is mummification, it is of the outer tissues only with internal organs lost through autolysis or insect activity. The last appearances within stage 3 include 
mummification with bone exposure of less than one half the skeleton and likely adipocere development.

Stage 4 is apparent when Skeletonization advances and the bones present with a coating of greasy substance. The tissues are decomposed yet sometimes body fluids are still present. Stage 4 advances to the point where the bones with desiccated tissue or mummified tissue represent less than one half of the skeleton. And finally, the bones become largely dry but still retaining some grease progressing to completely dry bone.

The final stage (stage 5) is referred to as Extreme Decomposition. In this stage, skeletonization is complete with bleaching of the bones apparent when found on or exposed to the surface. This progresses to skeletonization with exfoliation, skeletonization with metaphyseal loss with long bones and cancellous exposure of the vertebrae.

\section{Estimate of decomposition and mummification status}

According to the stages of decomposition presented by Galloway (4), the swine analog in the experimental tomb reached the middle of stage 3, advanced decomposition by day ninety-five. This determination was made from the appearance of some pupa activity, internal organs that were completely lacking in morphological integrity, and partial mummification and adipocere formation at the haunches. The progress of the subject's decomposition prior to day ninety-five is as follows: On day 1, the subject entered Stage 1, or fresh decay, immediately following its death, when no discoloration or insect activity was evident. By day nine, endoscopic and olfactory observation suggested that the subject had entered the end of Stage 2, early decomposition, evident from the rupture of abdominal gases, resulting in the appearance of a fluid trail at the base of the tomb. The subject most likely entered Stage 3, advanced decomposition on or around day 33 when the subject appeared significantly slumped from its original position suggesting caving in of the abdominal cavity and presence of moisture on the endoscope noted after observing the intra tomb changes.

The subject appears to have begun the decomposition process at a seemingly rapid rate, with the progress eventually slowing considerably throughout the experimental period. A study conducted by Shattuck (8) monitored the decomposition rate in swine analogues in central Texas exposed on the surface and reported the findings using the Galloway decomposition classification framework. Comparing the Shattuck results to the swine in the present study, we see a decomposition pattern at a somewhat slower rate due to the protected nature of the tomb burial. By day 2 in the Shattuck study, the abdominal cavities 
of the swine analogs had already ruptured, releasing gases and fluids, which was not observed until day 9 in the present study. In fact, Shattuck reported that the swine in the study entered advanced decomposition after 4 to 6 days. As previously stated, the swine in the present study appeared to be in the mid stage of advanced decomposition at exhumation on day 95 using the Galloway classification. Given these observations it appears that decomposition was slowed considerably due to the tomb interment.

Additionally, we observed significantly less insect activity when compared to that reported by Janaway et al. (7). Clearly the rapid interment and the limited exposure to the ambient environment due to the tomb structure used in the current study impeded the insect infestation rate and influenced the degree of decomposition observed. It is important to note that since Janaway only reported their results at the end of their 24-month experiment, it is not possible to correlate the rate of decomposition in our cadaver to the swine analogs in their study.

\section{Soil analysis and its potential impact on mummification}

The elemental analysis of the surface and deep tomb soil was unremarkable as it relates to this experiment. There did not appear to be a significant difference between the surface soil and the soil obtained from the bottom of the tomb. As seen in the results section, those elements, salts and heavy metals, were reported here. Soils high in salts are alkaline and tend to have a 'wicking' effect on decaying corpses. Such soil characteristics would encourage desiccation and potentially impede the decomposition process enhancing the chance of mummification. Tombs high in calcium carbonate found in limestone have been associated with natural mummification in various locations including subterranean crypts below churches in Europe and crypts in Mexico $(2,3,10)$. It is speculated that the hydroscopic characteristic of limestone causes it to act as a natural dehydrating substance. Heavy metals have also been associated with mummification of tissues when used both intentionally or when found in high concentrations in soils $(1,5)$.

In this study, the subject did not come into direct contact with the soils at any time, thus any direct impact on the rate of decomposition was thought to be negligible. Hydrated lime is used in the construction of the concrete fence block used to line the tombs in this study. Once dried, the lime may in fact absorb some of the moisture from within the intra-tomb space. Our data did not allow us to address this intra-tomb feature. 


\section{Temperature and $\mathrm{RH}$ comparison of between tombs}

It was not surprising to find that the average intra-tomb temperature and $\mathrm{RH}$ was higher in the experimental tomb when compared to the control intra-tomb data. It is known that a decomposing body will give off both heat and humidity raising these variables when measured. What the data does demonstrate is a quantification of that variance between the experimental and control intratomb environments. The fact that the variables were statistically significantly different from one another helps verify the behavior of the intra-tomb environment holding a swine analogue as being different from an identical but empty comparison tomb. The tomb appears to play some role in determining the rate of decomposition and the potential for mummification in that it creates a void into which moisture and heat can dissipate from the body. This may allow for more rapid dehydration impeding decomposition and encouraging desiccation.

\section{Varied stages of mummification as related to gravity dependence}

The experimental subject of our study advanced to the mid to latter part of the advanced decomposition stage (stage 3) of Galloway's (4) decomposition scale for Sonoran Desert regions. At day 95, upon exhumation, it was interesting to find that the corpse was clearly in various states of decay. This variability was due to the gravity dependent characteristics associated with the upright sitting position of interment. As reported in the results section of this paper, the head and neck regions were stiff and in the early stages of mummification. The torso presented with caseous internal organs suggesting the putrefaction stage of decomposition. The most gravity dependent portions, the haunches, appear to have undergone some degree of saponification usually seen in the butyric fermentation stage or Galloway's (4) late advanced decomposition stage 3. While no insect infestation was observed during the observational period, a few pupa casings were discovered at exhumation.

The finding of a pattern of varied states of preservation was not surprising. Guillen (5) reports that in natural mummification, gravity and body position can markedly influence the manner and pattern of mummification. As the body fluids migrate to the more gravity dependent regions, the bacteria and insect activity in the non-gravity dependent regions would be robbed of the fluid needed to advance decomposition. Thus, those body parts would mummify earlier than the body parts in the gravity dependent position. Further, internal organ decomposition would also occur at a greater rate in the gravity dependent regions. All other tissues, those of the extremities and internal organs positioned higher in the body, would decompose or mummify relative to the internal autolytic activity. Adipocere formation, particularly in the deeper tissues, is resistant 
to chemical change and taphonomic deterioration and is considered a form of tissue preservation (1). Janaway et al. (7) also observed varied stages of desiccation between the upper and lower portions of an upright corpse, specifically, moist tissue remaining near the haunches and evidence of mummification in more superior regions at the time of exhumation.

\section{Predation attempts}

On day nine, attempts at predation were evident. Scat and prints were observed near the experimental tomb. The control tomb was left undisturbed. Fortunately, it appeared that any predation attempts were unsuccessful. In order to prevent further predation attempts, on day 10 a dry blood and bone mixture along with dry coyote urine was distributed onto the topsoil around the perimeter of the experimental tomb (approximately $50 \mathrm{~g}$ per handful, completely surrounding the tomb). It was our intention to simulate a fresh kill in the area to ward off any curious scavengers. This method proved successful as no further predation in the direct vicinity of the experimental tomb was observed. We did note that over the course of the experiment, animal droppings appeared in the more general area away from the organic repellents.

\section{CONCLUSIONS}

This experiment demonstrated that the tomb structure had a significant impact on the rate of decomposition and the potential for complete mummification. The findings suggest that the tomb itself may have been a key feature of the natural mummification of individuals among the ancient Chiribaya culture. While previous studies have documented that rates of decomposition vary greatly based on such factors as time of year, climatic conditions, predation, insect invasion, surface versus sub-surface burials, depth of burials and enclosure interments, this study sheds light on the rate of decomposition specific to individual tomb burials in the Sonoran Desert.

The researchers acknowledge several limitations to this study. Among them are the differences between the Sonoran and Atacama Deserts in terms of relative humidity, annual rainfall and soil characteristics. The length of the study did not allow us to examine the body for an extended interval as seen in the Janaway study (7). With an extended period there is a potential that further mummification would have been seen. The swine analogue, while used in various decomposition experiments, was of course, not a human cadaver. Human remains may have a significantly different decomposition or mummification pattern when subjected to the conditions associated with this study. The swine 
fardo used in this experiment was a single layer of $100 \%$ wool while the Chiribaya often used multiple layers of textiles to wrap their dead. Also, the periodic opening of the PVC access port for endoscopic examination may have impacted the rate of decomposition. However, due to the lack of insect infestation seen at exhumation, the exposure associated with the viewing port openings appears negligible.

More work needs to be conducted to further assess the intra-tomb environmental characteristics in varied locations and scenarios to better understand the role such tomb environments play in natural human mummification. Ideally, a human cadaver would be employed in the actual Atacama Desert using fardo materials more representative of the Chiribaya body wrapping practices and using natural local materials such as river stones for tomb construction. With that said, this study has demonstrated that the tomb structure, along with additional factors, may contribute to impeding decomposition and encouraging mummification.

\section{ACKNOWLEDGEMENTS}

University of Arizona West Campus Agricultural Center; Arizona State Museum, University of Arizona; Department of Anthropology, University of Arizona; Bioanthropology Research Institute, Quinnipiac University; Skyline Laboratories of Tucson, Tucson, Arizona; Katherine J. Harper-Beckett; Kendyl Reisinger; Cody Dees; Mariel Watt; Juan Garcia; Rosalind Garcia.

\section{REFERENCES}

1. Aufderheide A.C. (2003). The Scientific Study of Mummies. Cambridge University Press. Cambridge.

2. Beckett R.G., Conlogue G.J. (2010). Paleoimaging: field applications for cultural emains and artifacts. CRC Press. Boca Raton, FL.

3. Cockburn A., Cockburn E., Reyman T.A. (1998) (eds). Mummies, Diseases \& Ancient Cultures. $2^{\text {nd }}$ edition. Cambridge University Press. Cambridge.

4. Galloway A. (1997). The process of decomposition: a model from the ArizonaSonoran desert. In: Haglund W.D., Sorg M.H. (eds), Forensic Taphonomy: The Postmortem Fate of Human Remains. CRC, Boca Raton, FL, 139-150.

5. Guillen S. (2004). Artificial mummies from the Andes. Coll. Anthropol, 28, 2, 141-147.

6. Holiday D.M. (2003). Archaeoparasitology of the Chiribaya of Southern Peru, with an Examination of Possible Health Implications, Master's Thesis. Quinnipiac University. Hamden. 
7. Janaway R., Wilson A., Carpio Diaz G., Guillen S. (2009). Taphonomic changes to the buried body in arid environments: An experimental case study in Peru. In: Ritz K. Dawson L., Miller D. (eds), Criminal and Environmental Soil Forensics,Springer Science. London, 341-356.

8. Shattuck C. (2009). An analysis of decomposition rates on outdoor surface variations in central Texas. Master's Thesis. Texas State University. San Marcos.

9. Vass A.A. (2001). Beyond the grave - understanding human decomposition. Microbiology Today, 28, November.

10. Ventura L., Leocata P., Beckett R., Conlogue G., Sindici G., Calabrese A., Di Giandomenico V., Fornaciari G. (2002). The Natural Mummies of Popoli. A New Site in the Inner Abruzzo Region (Central Italy). Antropologia Portuguesa, $19,151-160$.

\section{Address for correspondence:}

Prof. Ronald G. Beckett

Bioanthropology Research Institute

Quinnipiac University

Biomedical Sciences Faculty

275 Mount Carmel Avenue, Hamden, Connecticut, 06518 USA

E-mail: ronald.beckett@quinnipiac.edu 